\title{
Financial Crisis and International Portfolio Diversification: A Principal Component Analysis Approach
}

\author{
Sudhakara Reddy Syamala*, Kavita Wadhwa \\ IBS Hyderabad, IFHE University, Hyderabad, India \\ Email: "srsudhakar@ibsindia.org
}

Received 14 March 2016; accepted 26 April 2016; published 29 April 2016

Copyright (C) 2016 by authors and Scientific Research Publishing Inc.

This work is licensed under the Creative Commons Attribution International License (CC BY). http://creativecommons.org/licenses/by/4.0/

\section{(c) (i) Open Access}

\begin{abstract}
The present study examines the co-movement of selected world market stock indices in order to analyze the potential gains that Indian investors can achieve when they diversify their portfolio into international markets. The sample consists of a mix of different categories of world markets such as the matured markets like the USA, Japan, and UK, emerging markets like India, Singapore, South Korea, and Thailand with an inclusion of other world markets to cover more or less all the markets of the world. We examine the co-movement using principal component analysis which is useful in terms of stability of factors and it is unlikely that factor stability can be observed over longer periods. We examine the co-movement for a period of 15 years from 2000-2015. The results here suggest that there was a different pattern in the world markets before and after the financial crisis and the best portfolio for an Indian investor is Germany, Malaysia, Jakarta, Mexico, and Israel would appropriate.
\end{abstract}

\section{Keywords}

International Portfolio Diversification, India, Co-Movement, Principal Component Analysis

\section{Introduction}

Over the last decade, there has been a rapid growth in all the stock markets of the world. Between 1995 and 2015, the total size of global capital markets rose to $115 \%$ to \$US140tr. McKinsey Global institute forecasts markets will grow to around \$US230tr by 2016. Capital has been flowing across the borders in the form of

"Corresponding author.

How to cite this paper: Syamala, S.R. and Wadhwa, K. (2016) Financial Crisis and International Portfolio Diversification: A Principal Component Analysis Approach. Theoretical Economics Letters, 6, 338-346. 
equity (direct and portfolio), debt and financing from banks also increased very strongly ${ }^{1}$. Japan, China and oil rich countries make up a large portion of the global savings pool. The United States continue to account for almost two-thirds of global capital imports. The capital markets reached \$A3tr in 2005, up 173\% on a decade earlier and in US they are slightly deeper than the global average at 322\% of GDP in 2005. The Global trading in exchange and over the counter regarding the derivatives experienced a very rapid growth.

In this scenario, it pays for an investor to diversify his risk at an international level till the point where the stock returns of all the stock market do not have perfect correlations. Modern portfolio theory deals with the aspects of international portfolio diversification. The investor by diversifying internationally will be in a position to reduce his risk, compared to intra-national diversification by getting rid of individual country risk which results in the reduction of the systematic risk and is exposed to the world risk alone. Hence the integration and co-movement of stock indices of the world markets interests many portfolio managers, fund managers and also the individual investors who want to gain decent returns from their portfolios.

The objective of this study is to extend the determination of co-movement among the selected world market stock indices in order to analyze the potential gains that Indian investors can achieve when they diversify their portfolio into international markets. The sample consists of a mix of different categories of world markets such as the matured markets like the USA, Japan, and UK, emerging markets like India, Singapore, South Korea, and Thailand with an inclusion of other world markets to cover more or less all the markets of the world. This study will be different from previous studies with regard to the consideration of the world markets and most importantly the study is different in a way that this analysis is done by taking the data of the world indices before and after the global financial crisis. Hence this study also gives an insight into the change in dynamics of the world markets after the financial crisis.

The main motivation for the study is that even though there were a lot of studies in the past on international diversification, there are no studies which have been done after the recent global financial crisis. So, it will be interesting to look at the change in dynamics of the world markets after the crisis and how the world markets are moving. There are no past studies in this area with respect to Indian investor with an exposure to almost all the major world markets. Generally the studies of this kind are done by sophisticated time series tests like Granger causality, cointegration, VECM. So, an attempt is made in the present paper to examine international diversification using principal component analysis.

\section{Literature Review}

There are broadly three categories of literature on stock market Integration and International portfolio diversification. The first category of studies also called as "contagion effect" simply examines integration on the basis of economic fundamentals. It explains the stock market interrelationships to determine how a specific group or individual stock markets are interdependent. The second category of research also termed as "Economic Integration" is interested in finding out the interrelationships and the possible changes in such relationships based on the facts that more the economies of two countries are related, more the influence on stock market returns, interest rates and inflation. The third and last category of studies based on the "stock market characteristics" such as industrial similarity, volatility and market size tries to explain why stock markets are interdependent by either decomposing or modeling stock market correlations [1].

\subsection{Studies on Contagion Effect}

The first category that is, the studies of contagion effect are studied by various authors for a long time. Sharma and Kennedy [2] made an attempt to test the random-walk hypothesis by applying the technique of runs analysis and spectral densities by examining the price behavior of Indian market with US and London stock markets. By observing monthly indices over a period of 11 years starting from 1963 to 1973, they found that the behavior of Bombay Variable Dividend Industrial Share Index (BVDIS) was statistically indistinguishable from that of London Financial Time-Actuaries 500 Stock Index and S \& P's 425 Common Stock Index. Their spectral densities estimated for the first difference series of each index confirmed the randomness of the series. The conclusions from the tests are that stocks listed on the Bombay Stock Exchange follow a random walk behavior and are equivalent with the stock price behavior of other stock markets of advanced industrialized countries, like US and

\footnotetext{
${ }^{1}$ Australia and Capital Market Evolution, Distinguished Speaker Seminar Series, Australian Stock Exchange (ASX).
} 
UK. Jorion et al., [3] have examined issue of segmentation versus integration of the Canadian equity market relative to global North American market. Monthly data for rates of return on the Canadian stocks were taken from January 1963 to December 1982. As far as the main findings of the study are concerned, the authors rejected the joint hypothesis of integration of the North American markets.

Taylor and Tonks [4] used the bivariate co-integration technique by Engle and Garner (1987), and found that there was a co-integration between the stock price index of the UK with the stock price index of the US, Germany, Netherlands, and that of Japan for the period between 1976 and 1986. They could not find any cointegration of the stock price indices of these countries in the period between 1973 and 1979. By taking the monthly stock price indices from 1971 to 1988 of US, Japan and Indian stock markets Rao and Naik [5] studied the inter-relatedness of these markets. They tried to cover the episode of the October, 1987 world market crash and the Indian stock market boom of 1985-1987 and subsequent fall in 1987-88 in their study period. By applying the cross-spectral analysis they concluded that the interrelationship among the three markets were, in average, very low. Choudhury [6] tried to examine the relationship among Asian Newly Industrialized Economies (NIEs), Japan, and the US by using the daily data for the period between 1986 and 1990. The author used variance decomposition and impulse response functions and found that the US led the NIEs and that there were significant linkages between the markets.

Amanulla and Kamaiah (1995) attempted to examine the stock market efficiency by measuring the integration among different exchanges in Indian Stock Market. The data used was the RBI monthly aggregate share indices relating to the all India, and five selected regional stock exchanges, viz., Bombay, Calcutta, Madras, Delhi and Ahmedabad during the period 1980-1993. By using two market integration approaches, such as, Ravalli on approach and Cointegration and error correction approach they concluded that Bombay, Madras and Calcutta stock exchanges were integrated and thus not efficient. But Ahmedabad and Delhi stock exchanges confirmed the existence of market efficiency at the sense that these stock markets were not integrated during the study period. Angela Ng. [7] had tried to examine the magnitude of changing nature of volatility spillovers from Japan and the US to six Pacific-Basin equity markets. Weekly data relating to equity indices, in terms of US dollars, were used. The indices used are the Hang Sang Index (Hong-Kong), the Korean Composite Stock Price Index, the Kuala Lumpur Stock Exchange Composite Index, the Stock Exchange of Singapore All Share Index, the Taiwan Stock Exchange Weighted Price Index, Stock Exchange of Thailand Index, the Tokyo Stock Price Index and the S \& P's 500 Index. Their study consists of various tests based on the ARCH family of model developed by Engle (1982) and generalized by Ballerrslev (1986). Bivariate GARCH $(1,1)$ model was used for the Japanese and the US returns, while univariate Volatility Spillover model for the Pacific-Basin markets. The authors concluded that both regional and world factors, influenced by important liberalization events, were important for market volatility in the Pacific-Basin regions. Again, their findings showed that Japanese and the US shocks together account for less than 10 per cent of the weekly variation in returns.

Roca and Selvanathan [8] analyzed the linkages between the equity market of Australia and those of Hong Kong, Singapore and Taiwan. They used the Granger-causality, Variance decomposition and impulse responses analysis based on the MSCI database between the period 1975 and 1995 . The results showed that the Australian stock market is not significantly linked with any of these markets. Chang (2002), by using daily closing price indices from 1995 to 1999 tried to explore whether there exist any long-run benefits from equity diversification for investors who invest in two Chinese share markets, namely those of Shanghai and Shenzhen Stock Exchanges. In order to test the integration between the markets they used three tests, namely the Multivariate Trace statistics, Harris-Inder approach, and the Johansen method. All the tests used by them suggested that these two Chinese share markets are not pair wise co integrated with each other. In other words, there were no long-term linkages between these two Chinese share markets and thus there exist potential for investors from diversifying in these two Chinese share markets. Bose and Mukherjee [9] tried to examine the integration of Indian stock market using tests like pair wise and group wise co-integration and Granger-Causality with the developed markets of the world such as US, Japan and other Asian markets. They used the daily closing price indices data from January 1999 to June 2004. Their results suggest that the degree of integration that is found to be not very high implies that the nature of integration with emerging Asian markets does not yet warranty any immediate concern for India regarding possible contagion and also shows that there is still much scope for reaping benefits of portfolio diversification, by investing in Indian markets.

The above studies focused only on the existence of inter-linkages between various markets. But another set of studies focused not only on the inter-linkages between the stock markets but also on various international and 
national events such as the 1987 October stock markets crash which affected the stock markets worldwide. They also studied the evolution of stock market relationships.

\subsection{Studies Related to Stock Market Crashes and Diversification}

Neal (1987) tried to examine the working of international capital markets between Amsterdam and London in the early eighteenth century. The author used the bi-weekly stock price data from August 9, 1973 to December 19, 1974. The Auto Regressive Moving Average Model (ARMA) which is a standard estimation technique was used for the price changes. The conclusion was that London and Amsterdam stock markets were efficient and well integrated from second quarter of eighteenth century onwards. Campbell and Hamao [10] tried to study the integration of long term capital markets in US and Japan by using the predictability of monthly excess stock returns on US and Japanese equity portfolios over the US Treasury bill rate. Stock prices and dividends are taken from the Centre for Research on Security Prices (CSRP) in case of US and for Japan from the available stock price indexes of Nekkei 225. Auto correlation methodology was used and they could find out that there is common movement of expected excess returns which suggest that there is at least a partial integration of US and Japanese stock markets. Faff and Mitto [11] examined whether capital market integration varies across industries. They have considered Australia, Canada and US capital markets and used matched sample design where companies are matched by size and industry. The tests were conducted in the Capital Asset pricing model and multi-factor pricing frameworks between 1983 and 1992. The results suggest that the global industry stocks such as oil and mining stocks are priced in a relatively integrated while regional industry stocks such as consumer and capital goods stocks are priced in segmented markets and also the Australian stocks were priced in different markets than the Canadian and US stocks prices. These findings also suggest the notion that economic and trade linkages are a dominant factor in international asset pricing.

Hardouvelis et al., [12] tried to study the evidence linking the process of increased integration of European stock markets in the 1990s to the prospects of the formation of EMU and the adoption of the euro as the single currency. They used weekly, deutschmark denominated, dividend-adjusted, and continuously compounded stock returns based on Friday closing prices in the $11 \mathrm{EU}$ countries. The weekly risk-free rate is the German Eurocurrency rate. Belgium and Luxembourg are aggregated into one market. The period of study was between February 7, 1992 and 26 June 1998. They concluded that UK market showed no signs of increased integration with the EU stock market and the integration in Europe was a Euro-specific phenomenon which is independent of possible simultaneous world-market integration. Lagoarade et al., (2007) studied the stock market integration of MENA (Middle Eastern and North African) countries and its implications for international portfolio investment allocation by using four different co-integration methodologies. The study significantly rejected the hypothesis of a stable long-run bivariaterelation between each of these markets and the EMU, the United States, and a regional benchmark which indicated that there are significant diversification opportunities for the three categories of investors. They also concluded that these markets displayed heterogeneous reactions by extending the methodology to capture the effects of economic, financial, and political events.

Mukherjee and Mishra [13] tried to investigate the price co-movement and hence the inter-market relations among India and 22 other foreign countries from all over the world and also to find out the possible forces that affected the evolutions of such international stock market integration among India and other countries. Their study was done by using Geweke (1982) measures of feedback on the daily closing price index data over a period of 16 years from 1990 to 2005. The annual feedback measures revealed the evolution of inter-market relationship on the same day and/or the lead-lag relationship across days for all the pairs of Indian and other foreign markets. The contemporaneous Geweke measures indicate a significant same-day relationship among the stock markets in India with that of almost all other foreign markets considered in the study.

There are other studies which apart from concentrating on the examination and degree of interdependence of stock markets, concentrated on finding out why stock markets are interdependent. Most of the studies addressed this issue and they laid emphasis on decomposition of stock returns into country and industry effects, only a few of them have tried to examine the other economic variables that may drive stock market co-movement.

\subsection{Studies on Stock Market Integration Based on Economic Integration}

Meric and Meric [14] found empirical evidence that diversification across countries results in greater risk reduction than diversification across industries. Their inter-temporal stability tests indicated that the longer the time 
period considered the better proxies ex-post patterns of co-movement can be for the ex-ante co-movements of international stock markets. Their seasonality tests also signified that international stock market co-movements were stable in the September-May period and relatively unstable during the period from May to September. Chen and Zhang [15] attempted to explain the extent of stock market correlation with extent of bilateral trade. They calculated the correlations between the emerging stock markets of Korea, Malaysia, Thailand, Taiwan, the Philippines, and Mexico, and the developed markets of the US, Hong-Kong, Japan, Canada, Singapore, Australia, New Zealand, Austria, Belgium, Denmark, France, Germany, Italy, the Netherlands, Norway, Spain, Sweden, Switzerland and the UK. After dividing the world into four regions: the US, Europe, Japan and the Asian Newly Industrialized Economies (NIEs), they calculated each country's correlation with each region, and then tried to determine whether those correlations can be explained by the extent of bilateral trade between country and the region. Overall, they found that stock market interdependence was positively correlated with the extent of trade.

Gutierrez et al., [16] examined the linkages between two parallel stock exchanges trading the same shares in Colombia namely the Bogota Stock Exchange and the Medellin Stock Exchange. The empirical analysis was conducted by using monthly data of the stock prices of 13 companies during the period from January 1963 to June 2001. The authors concluded that the two stock exchanges can be best described as fully integrated over a period of almost four decades, so that arbitrage opportunities could have been exploited in the short-run but not in the long run. Furthermore, the analysis of the short-run dynamics of the models offers support to the view that the location of a company's headquarters appear to matter in stock price formation. Khoon [17] tried to study the capital mobility in Malaysia with three main trading countries, namely the US, Japan and Singapore by evaluating the consumption patterns in Malaysia. Malaysia’s annual data 1960-2000 on real private final consumption was used as a measure of the consumption variable and annual real GDP was used as a measure of the income variable. The GMM model was used to test the different equations. The results indicate that Malaysia exhibited a substantial amount of financial openness despite periodic exchange controls.

\section{Research Methodology}

The data relating to the study is collected for the period between April 12000 and March 31st 2015. The data of the closing daily stock index values of the countries under study is collected from their respective stock exchanges. The stock indices of the countries under study are Argentina, Australia, India, France, Germany, Hong Kong, Israel, Jakarta, Japan, Malaysia, Mexico, Netherlands, Singapore, Srilanka, UK and US.

Daily adjusted closing log returns for the stock indices for the sample period are calculated and principal component analysis is done under two different heads. One for the entire sample period between 01/04/2000 to $31 / 03 / 2015$. The second one by dividing the sample period into two sub-periods. One being, before the crisis i.e. before September 2008 and the second one from beginning of the crisis that is from September 2008 to March 2015. A principal component analysis methodology has been used for the study to group the indices into different groups. Principal component Analysis (PCA) methodology is used to convert a large number of variables which are correlated into less number of variables called Principal components or factors. In general, the first principal component accounts for as much as variability in the given data as possible. Hence, PCA helps to reduce the number of variables into less number of more meaningful uncorrelated variables.

In this study based on the different groups or components formed using PCA, taking the Indian index in one group the portfolio is formed by selecting one index from each of the other components or groups on the basis of return per unit risk of the different indices. The index in a group which has the highest return per unit risk is considered the best index to form the portfolio. Below given is Table 1 showing the mean returns, standard deviation and return per unit risk of the various indices under study. All the indices returns are negative in the sample period.

\section{Results and Discussions}

Daily returns have been calculated by taking the natural logarithm of the daily closing price relatives, i.e. $\mathrm{r}=$ $\ln \left(\mathrm{P}_{\mathrm{t}} / \mathrm{P}_{\mathrm{t}-1}\right)$. Testing of stationarity (unit root test) is done by using Augmented Dickey-Fuller test and found that all the indices are stationary which are not shown here. Now the principal component analysis is done on all the indices under study with the entire sample period under consideration. The results of the principal component analysis are shown in the following figure after extracting six components and the variance extracted by these six components is accounted for $83 \%$ and the rotation method used is varimax rotation with Kaiser Normaliza- 
tion (Table 2).

Based on the components the indices can be grouped as shown in Table 3.

So in this group format for and Indian investor perspective one country index from each group should be selected. In the first group there are six countries so to select one index we have to see the index which is giving the highest return per unit risk from Table 1 and Jakarta has highest return per unit risk of 0.08 and it has to be selected. Following the same pattern Germany is selected from the second group, Mexico from the third group, Malaysia and Israel from the fifth and sixth groups respectively. So, the best portfolio in the case of the entire sample is given in Table 4.

Table 1. Return per unit risk statistics.

\begin{tabular}{cccc}
\hline Indices & Mean Return & Standard deviation & Mean/unit risk \\
\hline ArgClose & 0.001 & 0.026 & 0.051 \\
Ausclose & 0.000 & 0.014 & 0.032 \\
Indclose & 0.001 & 0.024 & 0.062 \\
Fraclose & 0.000 & 0.017 & 0.012 \\
Gerclose & 0.001 & 0.018 & 0.033 \\
Hkclose & 0.001 & 0.021 & 0.035 \\
Isrclose & 0.001 & 0.018 & 0.058 \\
Jakclose & 0.002 & 0.021 & 0.080 \\
Japclose & 0.000 & 0.019 & 0.011 \\
Malclose & 0.001 & 0.014 & 0.047 \\
Mexclose & 0.001 & 0.018 & 0.082 \\
Nethclose & 0.000 & 0.019 & 0.002 \\
Singclose & 0.001 & 0.017 & 0.040 \\
Skclose & 0.001 & 0.020 & 0.041 \\
Ukclose & 0.000 & 0.015 & 0.021 \\
Usclose & 0.000 & 0.015 & 0.014 \\
\hline
\end{tabular}

Table 2. Principal components for the sample period 2000 to 2015.

\begin{tabular}{ccccccc}
\hline Index & Comp 1 & Comp 2 & Comp 3 & Comp 4 & Comp 5 & Comp6 \\
\hline ArgClose & 0.152 & 0.198 & 0.762 & 0.108 & 0.193 & 0.252 \\
Ausclose & 0.792 & 0.253 & 0.066 & 0.073 & 0.101 & 0.204 \\
Indclose & 0.360 & 0.233 & 0.086 & 0.834 & 0.060 & 0.097 \\
Fraclose & 0.258 & 0.889 & 0.240 & 0.122 & 0.085 & 0.142 \\
Gerclose & 0.240 & 0.842 & 0.290 & 0.114 & 0.035 & 0.064 \\
Hkclose & 0.724 & 0.198 & 0.181 & 0.389 & 0.185 & 0.160 \\
Isrclose & 0.325 & 0.285 & 0.152 & 0.151 & 0.071 & 0.839 \\
Jakclose & 0.550 & 0.067 & 0.222 & 0.447 & 0.301 & 0.219 \\
Japclose & 0.846 & 0.277 & 0.034 & 0.044 & 0.107 & 0.088 \\
Malclose & 0.310 & 0.129 & 0.073 & 0.106 & 0.909 & 0.058 \\
Mexclose & 0.211 & 0.398 & 0.764 & 0.085 & 0.000 & -0.010 \\
Nethclose & 0.233 & 0.877 & 0.245 & 0.142 & 0.106 & 0.119 \\
Singclose & 0.677 & 0.225 & 0.245 & 0.405 & 0.211 & 0.107 \\
Skclose & 0.814 & 0.172 & 0.188 & 0.176 & 0.087 & 0.034 \\
Ukclose & 0.242 & 0.838 & 0.286 & 0.109 & 0.096 & 0.170 \\
Usclose & 0.079 & 0.499 & 0.734 & 0.056 & -0.047 & -0.011 \\
\hline
\end{tabular}




\section{Two Period Analyses}

With respect to the two period analyses entire sample period is divided into two parts and after applying the principal component analysis, the following components have been formed. Table 5 gives the principal components for the period from 01/04/2000 to 01/09/2008. Table 6 gives the principal components for the sample period from 01/09/2008 to 31/03/2015. Again based on the different components formed the indices are grouped into different groups. After that the ideal portfolio before and after the financial crisis is formed according to the criterion of highest mean return per unit risk.

The different indices of different countries are grouped based on the principal components as shown in Table 7.

The above table clearly indicates that dynamics of the world stock market indices are different before and after the crisis. So, due to the financial crisis the markets are not moving together as they were moving before the crisis and it can be concluded that the financial crisis has transformed the returns generated by the various indices and in the present situation (after crisis) the ideal portfolio of an Indian investor should be as Table 8 .

\section{Conclusion}

Indian investors and portfolio managers face more costs and higher risks in the international portfolio diversification and hence this study of the co-movement of stock indices between the various markets of the world is

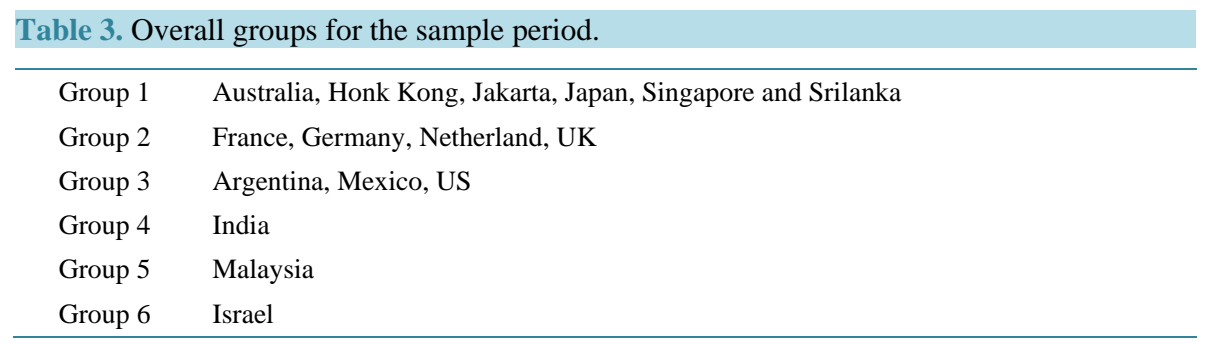

Table 4. Best portfolio for entire sample period.

Best Portfolio for entire sample period Jakarta, Germany, Mexico, Malaysia, and Israel

Table 5. Principal components for the sample period 01/04/2000 to 01/08/2008.

\begin{tabular}{ccccccc}
\hline Indices/Comp & 1 & 2 & 3 & 4 & 5 & 6 \\
\hline ArgClose & 0.061 & 0.087 & 0.747 & 0.213 & 0.432 & 0.008 \\
Ausclose & 0.751 & 0.214 & 0.077 & 0.149 & 0.104 & 0.071 \\
Indclose & 0.567 & 0.224 & 0.001 & -0.057 & 0.628 & 0.123 \\
Fraclose & 0.239 & 0.914 & 0.194 & 0.069 & 0.086 & 0.112 \\
Gerclose & 0.257 & 0.872 & 0.192 & 0.052 & 0.051 & 0.105 \\
Hkclose & 0.757 & 0.194 & 0.072 & 0.204 & 0.291 & 0.163 \\
Isrclose & 0.257 & 0.223 & 0.130 & 0.107 & 0.111 & 0.910 \\
Jakclose & 0.458 & 0.114 & 0.138 & 0.427 & 0.485 & 0.199 \\
Japclose & 0.842 & 0.217 & 0.097 & 0.060 & -0.033 & 0.065 \\
Malclose & 0.420 & 0.127 & 0.062 & 0.838 & 0.029 & 0.083 \\
Mexclose & 0.175 & 0.369 & 0.770 & 0.002 & -0.058 & 0.091 \\
Nethclose & 0.221 & 0.916 & 0.159 & 0.078 & 0.075 & 0.064 \\
Singclose & 0.726 & 0.257 & 0.122 & 0.289 & 0.234 & 0.108 \\
Skclose & 0.805 & 0.197 & 0.163 & 0.139 & 0.051 & 0.113 \\
Ukclose & 0.228 & 0.849 & 0.219 & 0.109 & 0.138 & 0.103 \\
Usclose & 0.161 & 0.504 & 0.672 & -0.067 & -0.186 & 0.143
\end{tabular}


Table 6. Principal components for the period from 01/09/2008 to 31/03/2015.

\begin{tabular}{ccccccc}
\hline Indices/Comp & 1 & 2 & 3 & 4 & 5 & 6 \\
\hline ArgClose & 0.221 & 0.426 & 0.671 & 0.226 & 0.180 & 0.163 \\
Ausclose & 0.797 & 0.327 & 0.034 & 0.053 & 0.075 & 0.241 \\
Indclose & 0.375 & 0.242 & 0.185 & 0.795 & 0.062 & 0.166 \\
Fraclose & 0.293 & 0.865 & 0.310 & 0.136 & 0.085 & 0.124 \\
Gerclose & 0.230 & 0.735 & 0.500 & 0.071 & 0.022 & 0.112 \\
Hkclose & 0.770 & 0.216 & 0.233 & 0.375 & 0.160 & 0.087 \\
Isrclose & 0.406 & 0.315 & 0.169 & 0.199 & 0.106 & 0.800 \\
Jakclose & 0.727 & 0.135 & 0.183 & 0.383 & 0.199 & 0.067 \\
Japclose & 0.845 & 0.359 & -0.019 & -0.011 & 0.128 & 0.123 \\
Malclose & 0.259 & 0.118 & 0.069 & 0.077 & 0.943 & 0.070 \\
Mexclose & 0.299 & 0.367 & 0.796 & 0.104 & 0.035 & 0.036 \\
Nethclose & 0.259 & 0.833 & 0.340 & 0.207 & 0.120 & 0.124 \\
Singclose & 0.716 & 0.187 & 0.317 & 0.417 & 0.146 & 0.076 \\
Skclose & 0.834 & 0.094 & 0.269 & 0.088 & 0.063 & 0.107 \\
Ukclose & 0.257 & 0.846 & 0.349 & 0.118 & 0.082 & 0.142 \\
Usclose & 0.048 & 0.388 & 0.844 & 0.095 & 0.004 & 0.062 \\
\hline & & & & & &
\end{tabular}

Table 7. Overall grouping of the indices.

\begin{tabular}{ccc}
\hline Group & Before Crisis & After Crisis \\
\hline Group 1 & $\begin{array}{c}\text { Australia, India, Japan, Singapore, } \\
\text { Srilanka, Hong Kong }\end{array}$ & $\begin{array}{c}\text { Australia, Hong Kong, Jakarta, Japan, } \\
\text { Singapore, Srilanka }\end{array}$ \\
Group 2 & France, Germany, Netherland, UK & France, Germany, Netherlands, UK \\
Group 3 & Argentina, Mexico, US & Argentina, Mexico, US \\
Group 4 & Malaysia & India \\
Group 5 & Jakarta & Malaysia \\
Group 6 & Israel & Israel \\
\hline
\end{tabular}

\section{Table 8. Best portfolio after crisis.}

Best Portfolio after the Crisis

Jakarta, Germany, Mexico, Malaysia, and Israel

important to Indian investors. Principal component analysis gives us an easy way of selecting the foreign markets for the portfolio risk diversification. So, the results here suggest that there was a different pattern in the world markets before and after the financial crisis and the best portfolio for an Indian investor is Germany, Malaysia, Jakarta, Mexico, and Israel would appropriate. Factor analysis is useful in terms of stability of factors and it is unlikely that factor stability can be observed over longer periods. The length of the time period used to estimate the factors remains an unanswered question in the use of the factor analysis.

On the other hand the Markowitz techniques based portfolio optimization is constrained by the negative returns of most of the markets mainly due to the financial crisis. In this analysis only 16 countries have been taken into consideration and analysis can be done using more number of indices to achieve better portfolio diversification.

\section{References}

[1] Mukherjee, K.N. (2004) Review of Stock Market Integration: An International Perspective. ICFAI Journal of Applied Economics, July. http://ssrn.com/abstract=746304 
[2] Sharma, J.L. and Kennedy, R.E. (1997) Comparative Analysis of Stock Price Behavior on the Bombay, London \& New-York Stock Exchanges. Journal of Financial and Quantitative Analysis, 12, 391-413.

[3] Jorion, P. and Schwartz, E. (1986) Integration vs. Segmentation in the Canadian Stock Market. Journal of Finance, 41, 603-613. http://dx.doi.org/10.1111/j.1540-6261.1986.tb04521.x

[4] Taylor, M.P. and Tonks, I. (1989) The Internationalization of Stock Markets and Abolition of UK Exchange Control. The Review of Economics \& Statistics, 71, 332-336. http://dx.doi.org/10.2307/1926980

[5] Rao, B.S.R. and Naik, U. (1990) Inter-Relatedness of Stock Markets: Spectral Investigation of US, Japanese and Indian Markets- Note. Artha Vignana, 32, 309-321.

[6] Choudhury, A.R. (1994) Stock Market Interdependencies: Evidence from the Asian NIEs. Journal of Macroeconomics, 16, 629-651. http://dx.doi.org/10.1016/0164-0704(94)90004-3

[7] Angela, N. (2000) Volatility Spillover Effects from Japan and the US to the Pacific-Basin. Journal of International Money and Finance, 19, 207-233. http://dx.doi.org/10.1016/S0261-5606(00)00006-1

[8] Roca, E.D. and Selvanathan, E.A. (2001) Australia and the Three Little Dragons: Are Their Equity Markets Interdependent? Applied Economics Letters, 8, 203-207. http://dx.doi.org/10.1080/13504850150504612

[9] Bose, S. and Mukherjee, P. (2005) A Study of Interlinkages between the Indian Stock Market and Some Other Emerging and Developing Markets. World Economic Outlook, IMF, April.

[10] Campbell, J.Y. and Hamao, Y. (1992) Predictable Stock Returns in the United States and Japan: A study of Long-Term Capital Market Integration. The Journal of Finance, 1, 43-69. http://dx.doi.org/10.1111/j.1540-6261.1992.tb03978.x

[11] Mittoo, U.R. and Faff, R.W. (2001) Capital Market Integration and Industrial Structure: The Case of Australia, Canada and The United States (undated). EFMA 2000 Athens. http://ssrn.com/abstract=250175 http://dx.doi.org/10.2139/ssrn.250175

[12] Hardouvelis, G.A., Malliaropulos, D. and Priestley, R. (2006) EMU and European Stock Market Integration. Journal of Business, 1, 365-392. http://dx.doi.org/10.1086/497414

[13] Mukherjee, K. and Mishra, R.K. (2007) International Stock Market Integration and Its Economic Determinants: A Study of Indian and World Equity Markets. Vikalpa, 32, 29-44.

[14] Meric, I. and Meric, G. (1989) Potential Gains from International Portfolio Diversification and Inter-temporal Stability and Seasonality in international Stock Market Relationships. Journal of Banking and Finance, 13, 627-650. http://dx.doi.org/10.1016/0378-4266(89)90034-4

[15] Chen, N. and Zhang, F. (1997) Correlation, Trade and Stock Returns of the Pacific-Basin Markets. Pacific-Basin Finance Journal, 5, 559-577. http://dx.doi.org/10.1016/S0927-538X(97)00022-X

[16] Gutierrez, L. and Otero, J. (2007) Testing for Stock Market Integration in a Developing Economy: Colombia. Applied Financial Economics Letters, 3, 231-236. http://dx.doi.org/10.1080/17446540600993860

[17] Khoon, G.S. (2008) Consumption Correlation and International Capital Market Integration: Evidence from Malaysia. Applied Economic Letters, 15, 489-494. http://dx.doi.org/10.1080/13504850600675443 